Sanchez-Gordon, M.L., O'Connor R.V. and Colomo-Palacios, R., Evaluating VSEs Viewpoint and Sentiment Towards the ISO/IEC 29110 Standard: A Two Country Grounded Theory Study, IN Rout, T. and O'Connor, R.V. and Dorling, A. (Eds), Software Process Improvement and Capability Determination, CCIS 526, Springer-Verlag, 2015.

\title{
Evaluating VSEs Viewpoint and Sentiment towards the ISO/IEC 29110 Standard: A Two Country Grounded Theory Study
}

\author{
Mary-Luz Sanchez-Gordon ${ }^{1}$, Rory V. O'Connor ${ }^{2,3}$, Ricardo Colomo-Palacios ${ }^{4}$ \\ ${ }^{1}$ Universidad Carlos III de Madrid, Spain \\ mary_sanchezg@hotmail.com \\ ${ }^{2}$ Lero, the Irish Software Research Centre, Ireland \\ ${ }^{3}$ Dublin City University, Dublin, Ireland \\ Rory.OConnor@computing.dcu.ie \\ ${ }^{4}$ Ostfold University College, Norway \\ Ricardo.colomo-palacios@hiof.no
}

\begin{abstract}
The ISO/IEC 29110 standard has at its core a Management and Engineering Guide [1] which are targeted at very small entities (enterprises, organizations, departments or projects) having up to 25 people [2], to assist them unlock the potential benefits of using standards which are specifically designed to address their needs. This paper is concerned with understanding the issues that affect the adoption of software process standards by Very Small Entities (VSEs), their needs from process standards and their willingness to engage with the new ISO/IEC 29110 standard in particular. This paper bring together two complimentary studies undertaken in Ireland and Ecuador which pose questions to VSE management regarding opinions, attitude and sentiment towards the adoption of the VSE designed standard ISO/IEC 29110. A series of interviews were untaken in both countries counties with qualitative data analysis utilizing the grounded theory coding mechanisms, to produce a picture of the current situation. This paper serves as a roadmap for both researchers wishing to understand the issues of process standards adoption by very small companies and also for the software process standards community.
\end{abstract}

Keywords: VSE, ISO/IEC 29110, ISO, Standards, process improvement

\section{Introduction}

There are multiple approaches to organizing the software development process and multiple factors influencing the software development process [3], with two major ones being the traditional (or plan based), which rely primarily on managing explicit knowledge, and agile methods, which primarily rely on managing tacit knowledge and recognizes the importance of human interaction in the software process $[4,5]$. Due to the rich variety of software development settings (for example: the nature of the application being developed, team size, requirements volatility), the 
implementation of a set of practices for software development may be quite different from one setting to another [6].

Projects are the cornerstone of all business activities in small and very small companies. Firms must complete various projects to achieve their financial goals and obtain information. Business owners and managers have only one attempt executing a project successfully. Hence, the process must be carefully thought out and planned. In their study into why software projects fail [7] have shown that software specialists spend about 40 to 50 percent of their time on avoidable rework rather than on what they call value-added work, which is basically work that's done right the first time

Administering software development is usually achieved through the introduction of a software project management process. However, implementing software project management controls in very small software companies is a major challenge. This paper introduces the project management practices in the newly published ISO/IEC 29110 [1] standard Software Process Lifecycles for Very Small Entities. The following sections discuss the role of project management in general, the structure of ISO/IEC standard and its project management practices.

\subsection{Research Problem}

In the current economic environment software quality is increasingly being seen as a subject of concern for growth and evolution of software companies in general, no matter what the size. Further quality orientated process approaches and standards are maturing and gaining acceptance in many companies. However, the use of ISO/IEC systems and software engineering standards remains limited to a few of the most popular ones. VSE specific standards such as ISO/IEC 29110 Software Process Lifecycles for Very Small Entities has been developed to assist and encourage very small software organization in assessing and improving their software.

This paper is concerned with understanding VSEs issues regarding adoption of standards, their needs from process standards and their willingness to engage with the new ISO 29110 standards' in particular. Accordingly the research question addressed by this study is "What is the opinion, attitude, sentiment and feeling towards the potential benefits of adopting a VSE specific standard such as ISO/IEC 29110 by VSE management and staff?". In order to investigate this research question, the authors have conducted two complimentary studies, one in Ireland and the other in Ecuador, which pose questions to VSE management and staff regarding opinions, attitude and sentiment towards the adoption of the ISO/IEC 29110 standard.

This paper is divided into 5 sections. Section 2 presents the background study of the study and outlines ISO/IEC 2910 in detail. Section 3 explains the overall research processes that have been applied in this study. A section 4 discusses all the findings and results of the study. Section 5 presents some concluding remarks and discusses future work. 


\section{ISO/IEC 29110 Standard}

The ISO/IEC 29110 standard "Lifecycle profiles for Very Small Entities" [1] is aimed at addressing the issues identified above and addresses the specific needs of VSEs [810] and to tackle the issues of poor standards adoption by small companies [11-13]. The approach $[14,15]$ used to develop ISO/IEC 29110 started with the pre-existing international standard ISO/IEC 12207 dedicated to software process lifecycles. The overall approach consisted of three steps: (1) Selecting ISO/IEC 12207 [16] process subset applicable to VSEs of up to 25 employees; (2) Tailor the subset to fit VSE needs; and (3) Develop guidelines for VSEs.

The basic requirements of a software development process are that it should fit the needs of the project and aid project success [10]. And this need should be informed by the situational context where in the project must operate and therefore, the most suitable software development process is contingent on the context $[5,17]$. The core situational characteristic of the entities targeted by ISO/IEC 29110 is size, however there are other aspects and characteristics of VSEs that may affect profile preparation or selection, such as: Business Models (commercial, contracting, in-house development, etc.); Situational factors (such as criticality, uncertainty environment, etc.); and Risk Levels. Creating one profile for each possible combination of values of the various dimensions introduced above would result in an unmanageable set of profiles. Accordingly VSE's profiles are grouped in such a way as to be applicable to more than one category.

Profile Groups are a collection of profiles which are related either by composition of processes (i.e. activities, tasks), or by capability level, or both. The "Generic" profile group has been defined [10] as applicable to a vast majority of VSEs that do not develop critical software and have typical situational factors. This profile group does not imply any specific application domain, however, it is envisaged that in the future new domain-specific sub-profiles may be developed in the future. To date the Basic Profile [1] has been published, the purpose of which is to define a software development and project management guide for performing one project at a time.

Finally, the results obtained from systematic literature review of the ISO/IEC 29110 standard [18] show that there is an increasing interest on it.

\subsection{Engineering and management guide}

At the core of this standard is a Management and Engineering Guide (ISO/IEC 29110-5) [1] focusing on Project Management and Software Implementation. The purpose of the Project Management process is to establish and carry out in a systematic way the tasks of a software implementation project, which complies with the project's objectives in terms of quality, time and cost. Project Management generates a Project Plan to direct the software project. During the execution of the project Change Requests may cause revisions to the Project Plan. The project is the subject of Project Assessment and Control during the lifetimes of the project until the Software Implementation is complete and Project Closure occurs. 
Software Implementation (SI) produces a specified software system implemented as a software product or service. This process starts with the establishment of Software Requirements, after which Architectural and Detailed Design are produced. Software is the Constructed and verified using Integration and Test procedures. The final staged being product delivery to the customer.

Within ISO/IEC 29110, the purpose of the Project Management process is to establish and carry out in a systematic way the Tasks of the software implementation project, which allows complying with the project's Objectives in the expected quality, time and costs. It is intended to be used by the VSE to establish processes to implement any development approach or methodology including, e.g., agile, evolutionary, incremental, test driven development, etc. based on the VSE organization or project needs.

\subsection{Deployment and Implementation Assistance}

In order to assist with the deployment of ISO/IEC 29110 and to provide guidance on the actual implementation of ISO/IEC 29110-5 in VSEs a series of Deployment Packages and Implementation Guides have been developed to define guidelines and explain in more detail the processes defined in the ISO/IEC 29110 profiles [19].

A set of Deployment Packages (DP) (which are freely available from [20]) are a set of artifacts developed to facilitate the implementation of a set of practices, of the selected framework, in a VSE. A DP is not a process reference model (i.e. it is not prescriptive). The elements of a typical DP are: description of processes, activities, tasks, roles and products, template, checklist, example, reference and mapping to standards and models, and a list of tools. Packages are designed such that a VSE can implement its content, without having to implement the complete framework at the same time.

To date a series of pilot projects have been completed in several countries utilizing some of the deployment packages developed [21]. For example in France, a pilot study [22] was conducted with a 14-people VSE that builds and sells counting systems about the frequenting of natural spaces and public sites. Furthermore a series of studies have been conducted to understand the perceptions [23] and potential commitment [24] of VSE management towards ISO/IEC 29110 [25].

\section{The Research Process}

The investigation of stakeholder perception in VSEs towards the adoption of process standards and ISO/IEC 29110 in particular relies heavily on eliciting and understanding the views of those who manage and deploy the software processes in situ and the interpretation of these experiences and the reality of the situation under study. The study therefore, naturally lends itself to the application of qualitative research methods, as they are orientated towards how individuals and groups view and understand the world and construct meaning out of their experiences. Therefore, the need for a deep understanding of the issues in VSEs calls for a qualitative research 
approach. The objective of the present study is more focused on creating a detailed description rather than creating a theory, accordingly a pure Grounded Theory (GT) method is not applicable but only GT coding process will be used in order to assist researcher in analyzing present study data $[26,27]$. As depicted in Fig. 1, this study has four main phases. In the first two phases, the data collection processes in two countries are completed utilizing individual and focus group interviews. In the third phase, GT coding process was used in analysis data. Finally the data is interpreted and presented in this paper.

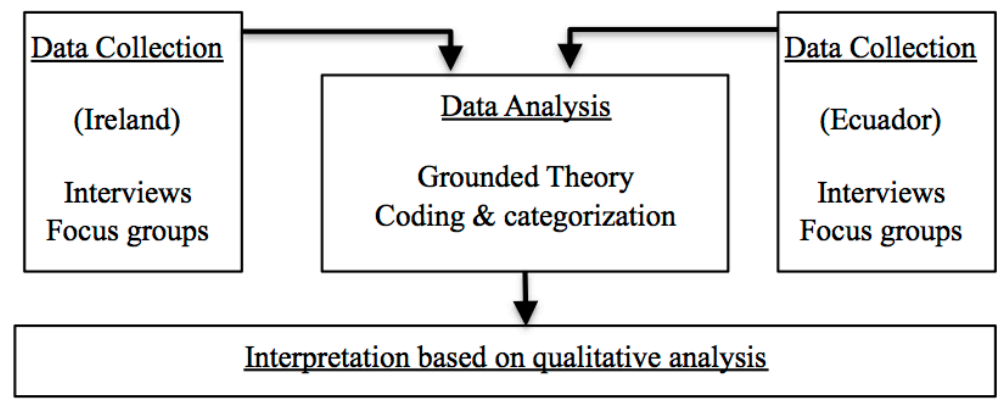

Fig 1. Research Process

\subsection{Data Collection Methods}

For quantitative data collection two complimentary data collection methods individual and focus group interviews. Interviews and Focus Groups are a resource-demanding data collection method; activities such as planning, conducting and analyzing are time-consuming by nature. However, interviewing people provides insight into their world; their opinions, thoughts and feelings and therefore we propose these as suitable data collections mechanisms. In particular focus groups explicitly use dynamic group interaction as part of the method to achieve enhanced data gathering, as it can for example activate details of forgotten experiences and also generate better data through wide range of responses. This means that instead of the researcher asking each person to respond to a question in turn, people are encouraged to talk to one another: asking questions, exchanging anecdotes and commenting on each other's experiences and points of view [28]. Both methods should be used properly and the sessions should be planned and executed well and with appropriate rigor in order to avoid potential sources for unwanted bias. Interviews and focus group were also recorded in order to prevent loss of information. Thus, the interviewer was able to pay more attention to the subject.

The individual interview approach was used in this study in order to discuss the topics in depth, to get respondents' candid discussion on the topic and to be able to get the depth of information of the study situation for the research context [28]. This process followed by semi-structured interviews approach which includes the openended and specific questions. This approach allowed us to gather not only the information foreseen, but also unexpected type of information. The respondents for 
the individual interview session are the managers from the identified Irish Software VSEs and went around 20 to 30 minutes in duration. Although, the approach carried out in Ecuador was tailored due to the language, cultural differences and actual development of the Ecuadorian software industry, the duration of the sessions is described in section 3.4. The use of semi-structured interviews is very frequent in the software engineering literature e.g. [29-31].

The second interview method is the focus group interview. It was used in this study because team members develop the software and the existence team interactions helped to release inhibitions amongst the team members and are from the same company as the individual interviews participants. Focus group interviews were also chosen because it was the most appropriate method to study attitudes and experiences; to explore how opinion were constructed and to understand behaviors, values and feelings [28]. Focus groups have been used in the past in software engineering scenarios as valid qualitative methods, e.g. [32, 33].

\subsection{Data Analysis Methods}

We followed the qualitative contents analysis method and adopted the Grounded Theory (GT) [34] data coding process to analyze all collected data and have a systematic data coding activities. This study has essentially employed the Strauss and Corbin [34] approach because the researchers have personal and professional experience on software development. It is supportive of theory building and contributes to "theoretical sensitivity", the ability to understand the data's important elements and how they contribute to theory. According to Strauss and Corbin [34], the theory that is derived from the data is more likely to resemble what is actually going on than if it were assembled from putting together a series of concepts based on experience or through speculation.

Data analysis may begin informally during interviews and continue during transcription, when recurring themes, patterns, and categories become evident. Coding is the key process in GT. It is the first step of data analysis and begins in the early stages after the first interviews for data collection. They assert that the coding procedures in GT are neither automatic nor algorithmic - "we do not at all wish to imply rigid adherence to them". Therefore, flexibility may be necessary in certain circumstances. There are two types of codes produced as a result of data analysis or coding. This process involves the development of the codes, code-categories and inter-relationship of categories which is based on the GT process and coding strategy. Three coding techniques proposed by GT methodology: open coding, axial coding and selective coding have been applied in order to assist researchers in analyzing qualitative data and are explained below in the context of this study. In this part all qualitative data gathered from individual interviews and focus group interviews were analyzed and coded. This process involves the development of the codes, codecategories and inter-relationship of categories based on the GT process and coding strategy [34]. 


\subsection{Study Participants}

Recruiting participants is a significant challenge for any research project as they have to spend time on what are often seen as a "non-productive" activity. As two of the authors has firsthand knowledge of their local software industry (ie. Ireland and Ecuador), potential candidates from commercial software VSEs were been identified through prior working relationships. In addition, in Ecuador an e-mail invitation was distributed to 30 enterprises of Ecuadorian Association of Software (AESOFT). Despite this effort, the organizations were selected based on availability therefore it was a crucial factor for their selection, which is a common practice [35].

To ensure participants were fully informed about the implications of their involvement in the research and to comply with the issue ethics, each potential VSE was provided with a research profile. In addition, each person who agreed to participate in the research project as an interviewee was asked to notify via e-mail that confirmed that they had understood the implications of their involvement and that they were willing to participate.

Within the Ecuadorian software community 3 VSEs, representing 3 interviews and 3 focus groups, took part in the fieldwork the semi-structured interview and focus group were performed. Within Ireland 6 Irish-based VSEs, representing 6 interviews and 6 focus groups, took part in the fieldwork the semi-structured interview and focus group were performed. In Ecuador the data collection process took 3 months and in Ireland 6 months, which included identifying suitable companies, contacting and confirming potential respondents' process, conducting individual and focus group interviews process.

\subsection{Conducting the Interview and Focus Group Sessions}

All of the interview and focus group sessions were conducted in a similar manner with one exception. In Ireland all interviews and focus groups were conducted in person at the VSE office location. However, in Ecuador on-line meetings were selected because the geographical location of the researchers (at the time of the study was conducted) and associated difficulties. Although these online forms provide many advantages over traditionally conducted meetings (e.g., savings in travelling and venue costs, participants feel more comfortable giving negative or controversial feedback), they also have distinct drawbacks, too, such as the task of the moderator can be much more demanding in online than in face-to-face settings [36].

The data was collected by conducting semi-structured interviews with Software Project Managers. Two interviews lasted approximately two hours and a half and one three hours. Conducting Semi-structured interviews instead of completely structured ones help with emergence of the real concerns of participants rather than forcing a topic that may be viewed as trivial by the participants. As the nature of the interviews had been open, when the conversation moved towards new and interesting areas relevant to the subject, the interviewer pursued and explored the new directions. Keeping this in mind, the focus group was performed with software developers, 
lasting from one hour and a half to two hours. Again, this approach was helpful to understanding of respondents based on data collected previously.

Every meeting was voice recorded and then transcribed. A complete transcription is very time consuming, but it avoids the loss of data. In this way, it was easier to recall the content clearly and to gain a thorough insight into the all the data material. The transcriptions were used for the coding of data in the subsequent analysis phase.

\section{Study Findings and Discussion}

From the qualitative data analysis process, which adopted the GT coding approach, we categorise the issues into several identified categories as shown in table 1 . The details of the main categories are presented below, which grouped and listed out in detail the important variable that was gathered from the analysis of understanding the actual software process development in very small companies.

Table 1. GT Themes, core categories and categories

\begin{tabular}{|c|c|c|}
\hline Sub Category & Category & Main Category \\
\cline { 1 - 2 } High Awareness on Standard & \multirow{2}{*}{$\begin{array}{c}\text { Level of Interest } \\
\text { and Awareness }\end{array}$} & Quality \\
Standard Benefit Awareness & Standard \\
\cline { 1 - 1 } Low Acceptable & Level of Acceptance & Aceptance \\
\cline { 1 - 1 } Less Priority & & \\
\cline { 1 - 1 } Perceived Need & Barriers Towards & \\
\cline { 1 - 1 } Resource Demand & Adoption & \\
\hline
\end{tabular}

\subsection{Level of Interest and Awareness}

This category explains VSEs level of interest and awareness regarding software quality standards in general and of ISO/IEC 29110 in particular. Our analysis has shown that there is an interest and awareness about software process standards and the potential benefits from having a quality standard especially the ISO standards. Leading to a quality product, create consistency, improve company image, create consistency in development work, improve work process and good for business are the main points that the interviewees gave, which indicates VSEs high awareness and interest about the benefit of having software quality standard. One company explicitly expressed that the company had planned to adopt the ISO 9000 but due to several constraints as have been discussed above made the plans to be put on hold. This situation shows that VSEs have an interest and are aware about the benefit adopting software quality standard. This level of interest and awareness is illustrated in the following interview extracts: "Yes we do plan too, but since we started we have growth so quickly... we spend time learning how we want to do... we started to put those processes in place so when we grow we have a good platform." and "They [software quality standard] are nice. It would be great to have them in order to have a consistence software process up and running." 
The analysis has also shown that there is an indicator that small companies are interested and are aware about software process and quality standards. The interviewed companies believe that the potential benefits from having a quality standard, and in particular ISO/IEC 29110, could be a quality product, improving company image, improving work process, creating consistency in development work, making the business more profitable because less time is spent on non-productive work. As one interview subject explained "I think it [standard] is necessary, let us not beat around the bush, but you have to adapt it to the reality of the company. As I told you, each reality is different ... so I have assumed few things and implemented few things because it is necessary. You cannot live without it". This concept was backed up by another who explained "If you could achieve the standard ... eventually you could decrease the costs because you would have a defined process". Finally a further participant remarked, "The great benefit is a more controlled software development process so take less time to finish ..."

\subsection{Level of Acceptance}

Based on the analysis of the data the researchers found that none of the VSEs are or have plans to adopt or accredited any particular standard in their software development process. Interview data analysis identified several reasons that have been divided to 2 main subcategories (Low Acceptable and Less Priority) in order to understand the problem in adopting standards. The first subcategory is on the low standard acceptable issues, which is due to the perception that process standards are overly involved / complicated and lacking in detailed implementation guidance.

The Level of Acceptance is low because none of the companies are accredited to or have plans to adopt any particular lightweight software quality standard. They argue that the software quality standards are not tailored with the current development process so it is a big challenge. The following three interview extracts describe this situation: "There is still a lot to do, to document"; "Many companies do not adopt the standards as they are cumbersome and will not have a return on investment"; and "I think the first step is to have our well-defined process, we probably need to have our own product, and I think the next step is to address the quality issues".

The second subcategory in this part is on the low priority issues. The interviews analysis also indicates that a software quality standard is a low priority task in software development process and activities in VSEs. The interviewees have explained several reasons, which indicate this situation. Not compulsory or low demand of the accreditation to standards from their client is the main reasons given by all the interviewees. Higher quality of code and delivery time are seen as more important that the evaluation of the development process. Software quality standards were seen as 'sale tool' only. They also responded that current software quality standard objective such as encapsulated in standards such as ISO 9000 are more toward on the management and services of the software development process rather than a software technical issues and product. They also believed that the software quality standards are built for the big companies rather than for VSEs. This is illustrated in these interview extracts: "If you want to get done quickly then what you need is focusing to the output not the process"; "A lot of process in quality standard 
is nonsense. Some ISO standards tell you to do XYZ steps but they may be not being beneficial to our business"; "We do informal research if we found something cool article I will try to followed to improve our process. But seriously standards quality is not on my list" and "Standard is just a sale tool."

\subsection{Barriers to Adoption}

This category explains the barriers to adoption in particular die to a lack of Perceived Needs and a high level of perceived Resource needs.

The data analysis indicates that VSE believe that they do not need it because they are small and have limited resources in the company. They were not interested in adopting any quality standard due to the cost, time and effort involved. In addition, there are perceived difficulties in implementing a new process that everyone can understand and follow clearly. One company in relation to CMMI explained such barriers as "These methodologies [such as CMMI] are still very large for our size. There are still a gap between our human resource and our financial resources". Another remarked on the effect of people related perceptions as barriers by stating that "I just tell you the people. People should be involved ... there is always resistance to change".

On a related point one participant highlighted the need for integration to counteract barriers by stating "You have to do it along with the daily work ... paper can withstand all but you have to put it into practice, too". Another company explained that "We made up our own methodology, it was adapted to our reality and it works, we need agility, unfortunately we also need to have formal documentation otherwise the customer relationships are complicated but I cannot overburden".

In addition, the adoption of standards would require additional resources which would have an additional cost to the company. Participants also believed that the processes as described in software standards are not easy to actually tailor and implement in these organizations. For example, the view was consistently expressed that current software quality standards such as ISO9000 cannot be adapted and followed. In relation to that, all the interviewees believed that involving or adapting software quality standard in their process will increase the project cost and delay the project delivery. Meanwhile, they argue that the process involved software quality standards are not tailored with the current development process, which are more brief, informal and very light in process. The following interview extracts describe this situation: "In a company of our size they [standards] would not necessarily add value... we would need more sophisticated process if we were a larger company"; and "Too much documentation and you need somebody to just work on the software process alone. Because our developers are busy with coding, documentation is the last thing they do."

Furthermore, the analysis also indicates that the lack of requirement from the market in general and their customer in particular has contributed to low acceptance of such standards. During the interviews it was also shown that accreditation against software quality standards is only important when companies involved or plan to work with the government bodies or state agencies that have such a requirement. Contributing to this is the fact that most VSEs clients are private, small or individual 
companies which do not have a standards accreditation requirement. The following interview extracts best describe this situation: "We had never had a problem selling our stuff or not selling our stuff because of an ISO standard. Microsoft Windows standard are sometimes important, but ISO who cares!" and "I never heard anything from sales that we couldn't sell anything because of lack of ISO standard.”

\subsection{Requirements of a Standard}

In order to understand more about software quality standards in VSEs, we asked the interviewees the criteria they considered important in a software quality standard. The purpose here is to understand in detail the criteria that VSEs consider is important in order to encourage among small companies the adoption of a software quality standard such as ISO/IEC 29110. The respondents indicated that it requires a number of issues to be addressed such as:

- Minimum overhead of resources (time, people and financial)

- More information about the standards such as guidelines, deployment packages and certification process scheme.

- Papers about case studies of its adoption in terms of time required, workload and lessons learned.

- Expert Assistance and detailed guidelines

- Provide clear templates

- Provide workshop and/or training on how to actually apply it

Although not all participants were knowledgeable in software quality standards, all of them agreed that ISO/IEC 29110 could be helpful. As a project manager in one of the companies, which is EFQM certified company, said: "I think and I am increasingly convinced that many past years with adequate knowledge could be compressed into a tablet ... we have done things differently".

\section{Conclusions}

The issues identified can be as: the level of acceptance, level of awareness and new standard criteria. The first category has prevailed that the acceptance level of any type or model of software quality standard in VSEs is very low and less priority. The reasons are mainly related to the low level of customer or market requirement, lack of resources and, lengthy and difficult procedures. However, the analysis also showed that the level of awareness of software quality standards and its advantage are high and there are some initiatives or plans to adopt in the not near future. The third category indicates the criteria needed or proposed by the VSEs, which include the detail guideline and assistance, less overhead and resources and aligned with VSEs current process, that must be aware in order to encourage or to attract VSEs seriously involved in software quality standards.

As ISO/IEC 29110 is an emerging standard there is much work yet to be completed. The main remaining work item is to finalize the development of the remaining profiles and the development of additional Profile Groups for other 
domains such as critical software, game industry [37], scientific software development are being studied. In addition, recently, the ISO working group was mandated to develop a standard for VSEs developing systems engineering [38, 39] and is investigating ITSM [40] and agile development approaches [41].

The relationship between the success of a software company and the software process it utilized has been investigated [42-44] showing the need for all organizations, not just VSEs to pay attention to software process practices such as ISO standards [45]. Here fore ultimately it is the position of the authors that standards such as ISO/IEC 29110 have a potential important impact on the software industry.

Acknowledgments: The Irish elements of this study were supported, in part, by Science Foundation Ireland grant 03/CE2/I303_1 to Lero, the Irish Software Engineering Research Centre (www.lero.ie).

\section{References}

1. International Organization for Standardization (ISO): ISO/IEC TR 29110-5-1-2 Software engineering - Lifecycle profiles for Very Small Entities (VSEs) Part 5-1-2: Management and engineering guide: Generic profile group: Basic profile., Geneva (2011).

2. Laporte, C.Y., Alexandre, S., O'Connor, R.V.: A Software Engineering Lifecycle Standard for Very Small Enterprises. In: O'Connor, R., Baddoo, N., Smolander, K., and Messnarz, R. (eds.) Proceedings of EuroSPI. pp. 129-141. Springer, Heidelberg (2008).

3. Ryan, S., O'Connor, R.V.: Acquiring and sharing tacit knowledge in software development teams: An empirical study. Information and Software Technology. 55, 1614-1624 (2013).

4. Ryan, S., O'Connor, R.V.: Development of a team measure for tacit knowledge in software development teams. Journal of Systems and Software. 82, 229-240 (2009).

5. Clarke, P., O'Connor, R.V.: The situational factors that affect the software development process: Towards a comprehensive reference framework. Journal of Information and Software Technology. 54, 433-447 (2012).

6. Jeners, S., Clarke, P., O'Connor, R.V., Buglione, L., Lepmets, M.: Harmonizing Software Development Processes with Software Development Settings - A Systematic Approach. In: McCafery, F., O'Connor, R.V., and Messnarz, R. (eds.) Systems, Software and Services Process Improvement. pp. 167-178. Springer-Verlag (2013).

7. Charette, R.N.: Why Software Fails. IEEE Spectrum. 42, 42-49 (2005).

8. O'Connor, R., Laporte, C.: Deploying Lifecycle Profiles for Very Small Entities: An Early Stage Industry View. In: O'Connor, R., Rout, T., McCaffery, F., and Dorling, A. (eds.) Software Process Improvement and Capability Determination. pp. 227-230. Springer-Verlag, Heidelberg (2011).

9. O'Connor, R., Laporte, C.Y.: Using ISO/IEC 29110 to Harness Process Improvement in Very Small Entities. In: O'Connor, R.V., Pries-Heje, J., and Messnarz, R. (eds.) Workshop on SPI in SMEs, 18th European Software Process Improvement Conference. pp. 225-235. Springer-Verlag, Heidelberg (2011).

10. O'Connor, R., Laporte, C.Y.: Towards the provision of assistance for very small entities in deploying software lifecycle standards. Proceedings of the 11th International Conference on Product Focused Software (PROFES '10). pp. 4-7. ACM (2010).

11. Coleman, G., O'Connor, R.: Investigating software process in practice: A grounded theory perspective. Journal of Systems and Software. 81, 772-784 (2008). 
12. O'Connor, R., Coleman, G.: Ignoring" Best Practice": Why Irish Software SMEs are Rejecting CMMI and ISO 9000. Australasian Journal of Information Systems. 16, (2009).

13. O'Connor, R.V.: Evaluating Management Sentiment towards ISO/IEC 29110 in Very Small Software Development Companies. In: Mas, A., Mesquida, A., Rout, T., O’Connor, R., and Dorling, A. (eds.) Software Process Improvement and Capability Determination. pp. 277-281. Springer-Verlag, Heidelberg (2012).

14. O'Connor, R.V., Laporte, C.Y.: An Innovative Approach to the Development of an International Software Process Lifecycle Standard for Very Small Entities. International Journal of Information Technology Systems Approach. 7, 1-22 (2014).

15. Laporte, C.Y., O'Connor, R., Fanmuy, G.: International Systems and Software Engineering Standards for Very Small Entities. CrossTalk - The Journal of Defense Software Engineering. 26, 28-33 (2013).

16. Clarke, P., O'Connor, R.: Harnessing ISO/IEC 12207 to Examine the Extent of SPI Activity in an Organisation. In: Riel, A., O'Connor, R., Tichkiewitch, S., and Messnarz, R. (eds.) EuroSPI 2010. pp. 25-36. Springer, Heidelberg (2010).

17. Jeners, S., O'Connor, R.V., Clarke, P., Lichter, H., Lepmets, M., Buglione, L.: Harnessing software development contexts to inform software process selection decisions. Software Quality Professional. 16, 35-36 (2013).

18. Moreno-Campos, E., Sanchez-Gordon, M.-L., Colomo-Palacios, R., Amescua Seco, A.: Towards Measuring the Impact of the ISO/IEC 29110 Standard: A Systematic Review. In: Barafort, B., O’Connor, R.V., Poth, A., and Messnarz, R. (eds.) Systems, Software and Services Process Improvement. pp. 1-12. Springer-Verlag, Heidelberg (2014).

19. Laporte, C.Y.: Contributions to Software Engineering and the Development and Deployment of International Software Engineering Standards for Very Small Entities (PhD thesis of the Universite de Bretagne Occidentale), (2009).

20. ISO/IEC JCT1/SC7 Working Group 24 Deployment Packages repository, http://profs.logti.etsmtl.ca/claporte/English/VSE/index.html.

21. O'Connor, R.V., Sanders, M.: Lessons from a Pilot Implementation of ISO/IEC 29110 in a Group of Very Small Irish Companies. In: Woronowicz, T., Rout, T., O'Connor, R.V., and Dorling, A. (eds.) Software Process Improvement and Capability Determination. pp. 243-246. Springer-Verlag, Heidelberg (2013).

22. Ribaud, V., Saliou, P., O'Connor, R., Laporte, C.: Software Engineering Support Activities for Very Small Entities. In: Riel, A., O’Connor, R., Tichkiewitch, S., and Messnarz, R. (eds.) Systems, Software and Services Process Improvement. pp. 165-176. Springer-Verlag, Heidelberg (2010).

23. Basri, S., O'Connor, R.V.: Understanding the Perception of Very Small Software Companies towards the Adoption of Process Standards. In: Riel, A., O'Connor, R.V., Tichkiewitch, S., and Messnarz, R. (eds.) Systems, Software and Services Process Improvement. pp. 153-164. Springer-Verlag, Heidelberg (2010).

24. O'Connor, R., Basri, S., Coleman, G.: Exploring Managerial Commitment towards SPI in Small and Very Small Enterprises. In: Riel, A., O'Connor, R., Tichkiewitch, S., and Messnarz, R. (eds.) Systems, Software and Services Process Improvement. pp. 268-279. Springer-Verlag, Heidelberg (2010).

25. Basri, S., O'Connor, R.: Organizational Commitment Towards Software Process Improvement An Irish Software VSEs Case Study. Proceedings of 4th International Symposium on Information Technology 2010 (ITSim 2010). pp. 1456-1461. IEEE, Malaysia (2010).

26. Hoda, R., Noble, J., Marshall, S.: Developing a grounded theory to explain the practices of self-organizing Agile teams. Empirical Software Engineering. 17, 609-639 (2012).

27. O'Connor, R.: Using Grounded Theory Coding Mechanisms to Analyze Case Study and Focus Group Data in the Context of Software Process Research. In: Mora, M, et al, (eds.) 
Research Methodologies, Innovations and Philosophies in Software Systems Engineering and Information Systems: pp. 256-270. IGI Global (2012).

28. Patton, M.Q.: Qualitative Evaluation and Research Methods. Sage Publications, Inc, Newbury Park, CA (2002).

29. Colomo-Palacios, R., Casado-Lumbreras, C., Soto-Acosta, P., García-Peñalvo, F.J., Tovar, E.: Project managers in global software development teams: a study of the effects on productivity and performance. Software Quality Journal. 22, 3-19 (2014).

30. Casado-Lumbreras, C., Colomo-Palacios, R., Ogwueleka, F.N., Sanjay, M.: Software development outsourcing: challenges and opportunities in Nigeria. Journal of Global Information Technology Management. 17, 267-282 (2014).

31. Herranz Sánchez, E., Colomo-Palacios, R., de Amescua Seco, A., Yilmaz, M.: Gamification as a disruptive factor in software process improvement initiatives. Journal of Universal Computer Science. 20, 885-906 (2014).

32. Colomo-Palacios, R., Soto-Acosta, P., García-Peñalvo, F.J., García-Crespo, Á.: A study of the impact of global software development in packaged software release planning. Journal of Universal Computer Science. 18, 2646-2668 (2012).

33. Colomo-Palacios, R., Casado-Lumbreras, C., Soto-Acosta, P., Misra, S., García-Peñalvo, F.J.: Analyzing human resource management practices within the GSD context. Journal of Universal Computer Science. 15, 30-54 (2012).

34. Strauss, A., Corbin, J.M.: Basics of Qualitative Research: Techniques and Procedures for Developing Grounded Theory. SAGE Publications, Inc, Thousand Oaks, CA (1998).

35. Benbasat, I., Goldstein, D., Mea, M.: The Case Research Strategy in Studies of Information Systems. MIS Quarterly. 11, 369-386 (1987).

36. Kontio, J., Lehtola, L., Bragge, J.: Using the focus group method in software engineering: obtaining practitioner and user experiences. Proceedings of the 2004 International Symposium on Empirical Software Engineering, ISESE'04. pp. 271-280. IEEE (2004).

37. O'Hagan, A.O., Coleman, G., O'Connor, R.V.: Software Development Processes for Games: A Systematic Literature Review. In: Barafort, B., O'Connor, R.V., Poth, A., and Messnarz, R. (eds.) Systems, Software and Services Process Improvement. pp. 182-193. Springer-Verlag (2014).

38. Laporte, C.Y., O'Connor, R.V., Barafort, B., O'Connor, R. V., Messnarz, R.: A Systems Process Lifecycle Standard for Very Small Entities: Development and Pilot Trials. Systems, Software and Services Process Improvement. Springer-Verlag (2014).

39. Laporte, C.Y., O'Connor, R.V.: Systems and Software Engineering Standards for Very Small Entities: Implementation and Initial Results. Proceedings of the 9th International Conference on the Quality of Information and Communications Technology (QUATIC). pp. 38-47. , Portugal (2014).

40. Mora, M., Raisinghani, M., O’Connor, R.V., Gomez, J., Gelman, O.: An Extensive Review of IT Service Design in Seven International ITSM Processes Frameworks: Part I. International Journal of Information Technologies and Systems Approach. 7 (2), (2014).

41. Galván-Cruz, S., Mora, M., Connor, R., Acosta-Escalante, F., Alvarez, F.: On project management process in agile systems development methodologies and the ISO/IEC 29110 standard (entry profile). International Conference on Informatics and Computing (CNCIIC-ANIEI). , Mexico (2014).

42. Clarke, P., O'Connor, R.V.: The influence of SPI on business success in software SMEs: An empirical study. Journal of Systems and Software. 85, 2356-2367 (2012).

43. Clarke, P., O'Connor, R.V.: Business success in software sMEs: Recommendations for future SPI studies. In: Winkler, D., O’Connor, R.V., and Messnarz, R. (eds.) EuroSPI 2012. pp. 1-12. Springer, Heidelberg (2012).

44. O'Connor, R.V., Basri, S.: Understanding the role of knowledge management in software development: a case study in very small companies. International Journal of Systems and Service-Oriented Engineering. 4, 39-52 (2014). 
45. O'Connor, R.V., Laporte, C.Y.: Software Project Management in Very Small Entities with ISO/IEC 29110. In: Winkler, D., O’Connor, R.V., and Messnarz, R. (eds.) Systems, Software and Services Process Improvement (EuroSPI 2012). pp. 330-341. SpringerVerlag (2012). 